\title{
PROCESSO, QUE PROCESSO?
}

\author{
José Ernesto Lima Gonçalves \\ Professor do Departamento de Administração Geral e \\ Recursos Humanos da EAESP/FGV e Consultor. \\ E-mail: jernesto@fgvsp.br
}

\section{RESUMO}

Este texto, uma continuação do artigo "As empresas são grandes coleções de processos" (Gonçalves, 2000), resume as diferenças entre as organizações tradicionais e as empresas estruturadas por processos, mostra os principais estágios em que as empresas podem estar no seu caminho em direção a organizações por processos e como identificar em qual deles a empresa está, estabelece as vantagens da gestão por processos sobre modelos tradicionais e apresenta argumentos objetivos e critérios que podem orientar a decisão das empresas pela mudança da sua maneira de organizar.

\section{ABSTRACT}

This text, a sequel of a previously published article (Gonçalves, 2000), states the differences between traditional organizations and process organizations. It shows the main stages in which companies may be on their way towards process organizations and how to identify the particular stage a company currently is. Besides, this article sets the advantages of managing by processes and presents objective arguments and criteria that can guide companies to make decisions about their organizational model.

\section{PALAVRAS-CHAVE}

Processos empresariais, processos de negócio, gestão por processos, organização por processos, dono do processo.

\section{KEY WORDS}

Processes, business processes, managing by processes, process organizations, process owner. 


\section{INTRODUÇÃO}

Muitas empresas querem organizar-se por processos, mas não têm uma noção clara dos passos a seguir e das providências que devem ser tomadas. Outras não estão certas da decisão a tomar a respeito da sua estruturação por processos e podem beneficiar-se de um raciocínio que as ajude a decidir. Existem também as empresas que não sabem ao certo o que significa serem organizadas por processos e as que não têm certeza se a sua forma organizacional atual é adequada para a gestão por processos. Finalmente, temos, ainda, as empresas que precisam de mais esclarecimentos sobre o assunto para que possam analisar as vantagens da gestão por processos.

Este texto, uma continuação do artigo "As empresas são grandes coleções de processos" (Gonçalves, 2000), resume as diferenças entre as organizações tradicionais e as empresas estruturadas por processos, mostra os principais estágios em que as empresas podem estar no seu caminho em direção a organizações por processos e sugere critérios que podem orientar a decisão das empresas pela mudança da sua maneira de organizar.

A empresa é a forma pela qual nós organizamos nossos recursos de todos os tipos para realizar o trabalho que nos propusemos a fazer. A estrutura de nossas organizações manteve-se basicamente a mesma durante várias décadas ao longo do século XX. Ela é herança da Revolução Industrial inglesa e foi reformada durante o surto industrial americano no começo do século. Esse tipo de organização assenta-se sobre vários pressupostos que estão superados e que deram base ao surgimento de empresas voltadas para dentro, para suas próprias atividades, com estruturas hierárquicas pesadas e rígidas (Gonçalves e Dreyfuss, 1995).

Empresas como a IBM, a HP e a Texas Instruments estão se organizando por processos no esforço para mudar de patamar em termos de desempenho empresarial, de atendimento aos seus clientes e de resultados para seus acionistas. As empresas estão procurando se organizar por processos ${ }^{1}$ para terem maior eficiência na obtenção do seu produto ou serviço, melhor adaptação à mudança, melhor integração de seus esforços e maior capacidade de aprendizado (Gonçalves, 1997a).

A idéia de processo não é nova na administração das empresas, mas é um novo entendimento que diz que o negócio precisa focar aquilo que pode ser feito para agradar aos clientes externos. Também é equili- brar o que é rentável para uma empresa a fim de não quebrá-la agradando aos clientes (Tendick, 1999).

Ao procurar estruturar-se por processos, as empresas acabam descobrindo que é impossível sobrepor um processo integrado a uma organização fragmentada pelo desenho funcional tradicional (Hammer e Stanton, 1999). As organizações estruturadas por tarefas precisam ser redesenhadas para poder funcionar por processos. Algumas empresas acabam dando alguns passos e desistem logo depois, sem saber ao certo como prosseguir.

\section{Muitas empresas não têm uma noção clara dos}

\section{passos a seguir para se organizarem por processos.}

As empresas percebem que é virtualmente impossível mudar de uma organização por tarefas para uma organização orientada por processos sem um claro entendimento do que exatamente faz a empresa funcionar bem e ter ritmo e notam que devem estar preparadas para uma nova maneira de fazer negócios. Um quadro claro dessa situação deve servir de ponto de partida para todos os subseqüentes alinhamentos de pessoas e processos dentro de uma empresa. É também vital garantir que a empresa não vá tomar iniciativas que desperdicem tempo, esforço e dinheiro (Tendick, 1999).

Identificar o processo como sendo a maneira típica de realizar o trabalho é importante para definir a forma básica de organização das pessoas e dos demais recursos da empresa (Dreyfuss, 1996). O processo é um conceito fundamental no projeto dos meios pelos quais uma empresa pretende produzir e entregar seus produtos e serviços aos seus clientes. Além disso, muitos dos processos nas empresas são repetitivos e envolvem, no seu conjunto, a maioria das pessoas da organização.

Nas empresas de serviços, por exemplo, o conceito de processo é de fundamental importância, uma vez que a seqüência de atividades nem sempre é visível, nem pelo cliente, nem pelas pessoas que realizam essas atividades (Gonçalves, 2000). Para o pessoal das empresas de serviços, os processos são seqüências de atividades que são necessárias para realizar as transações e prestar o serviço (Ramaswamy, 1996). A importância dos processos de trabalho aumenta à medida que as empresas ficam com conteúdo cada vez mais intelectual ou nas empresas de conteúdo puramente intelectual (Quinn, 1992), afastando-se do modelo fabril, de produção manufatureira. 


\section{COMO ENXERGAR OS PROCESSOS}

Muitos dos processos das áreas não fabris das empresas não são prontamente reconhecidos porque são pouco visíveis. O trabalho nos escritórios, por exemplo, segue fluxos que são conduzidos pelos cabos da rede informatizada, e não é tão facilmente observável o deslocamento do trabalho sendo realizado.

A distinção entre os processos de negócio e os processos auxiliares ou de suporte pode ajudar muito na identificação dos processos essenciais da empresa. Geralmente, os processos essenciais estão diretamente associados às regras básicas do negócio (Gonçalves, 2000). No caso de uma seguradora, por exemplo, a empresa propõe-se a garantir cobertura no caso de determinados sinistros ocorridos com os clientes selecionados com as quais ela faz contrato de seguro. Para isso, ela deverá: a) selecionar os clientes e fazer contrato de seguro com eles, b) reembolsar os pedidos de indenização por motivo de sinistro nos casos devidos e c) manter vínculo contratual com os clientes selecionados. Esses são os grandes processos essenciais numa seguradora-padrão.

Um caso real ilustra a dificuldade de as pessoas visualizarem os processos essenciais das empresas. O pessoal da Belofio, uma empresa industrial paulista fabricante de fios e malhas de algodão, por exemplo, levou 15 dias para entender seu processo essencial principal. Eles conseguiam identificar de imediato o processo fabril de fabricação dos fios e malhas, mas o processo essencial de atendimento dos pedidos dos clientes só foi bem compreendido depois de inúmeras reuniões com os participantes das diversas áreas funcionais da empresa (Figura 1).

A análise dos processos nas empresas implica a identificação das diversas dimensões desses processos: fluxo (volume por unidade de tempo), seqüência das atividades, esperas e duração do ciclo, dados e informações, pessoas envolvidas, relações e dependências entre as partes comprometidas no funcionamento do processo.

A idéia de hierarquia é fundamental para a identificação dos processos essenciais e para a análise sistêmica das organizações. De acordo com essa idéia, os processos podem ser agregados em macroprocessos e subdivididos em subprocessos ou grupos de atividades, e o nível de agregação mais adequado depende do tipo de análise que se pretende fazer.

\section{O PONTO DE VISTA DO CLIENTE}

As empresas convencionais foram projetadas em função de uma visão voltada para a sua própria realidade interna, sendo centradas em si mesmas. A implementação do ponto de vista do cliente na gestão das empresas praticamente exige que se faça o redesenho de seus processos de negócio. A adoção de uma estrutura baseada nos processos significa, em geral, dar menos ênfase à estrutura funcional da empresa (Davenport, 1994) e, na prática, exige o emprego de outros modelos organizacionais e de negócios (Gonçalves, 1998).

Para organizar a empresa por processos de negócio, precisamos colocar o foco no cliente externo, já que os processos de negócio começam e terminam nele. Os processos enxergam uma linha de atividades que começa com o entendimento exato do que o cliente externo deseja e termina com o cliente externo adquirindo o que ele precisa e deseja de um negócio.

O cliente está no centro das organizações por processos, e o objetivo final dessas empresas é oferecer para o cliente mais valor, de forma mais rápida e a um custo mais baixo. Nossas organizações atuais são um entrave para isso, e é necessário aprender a pensar em novas formas de estruturar as empresas. As pessoas precisam aprender a compreender o negócio, a assumir mais responsabilidades e a trabalhar em equipe (Hammer, 1998).

A noção de valor para o cliente é baseada na percepção da vantagem ou do benefício que ele recebe em cada transação com a empresa. Essa percepção depende, por exemplo, da relação entre o tempo de processamento e o tempo de ciclo. ${ }^{2} \mathrm{O}$ preço pago é apenas uma parte do esforço para obter o produto ou serviço. O cliente avalia também a rapidez e o conforto para obter o produto e a oportunidade de conseguir o que deseja. Nem sempre o valor para o cliente

Figura 1 - O processo de atendimento dos clientes da Belofio

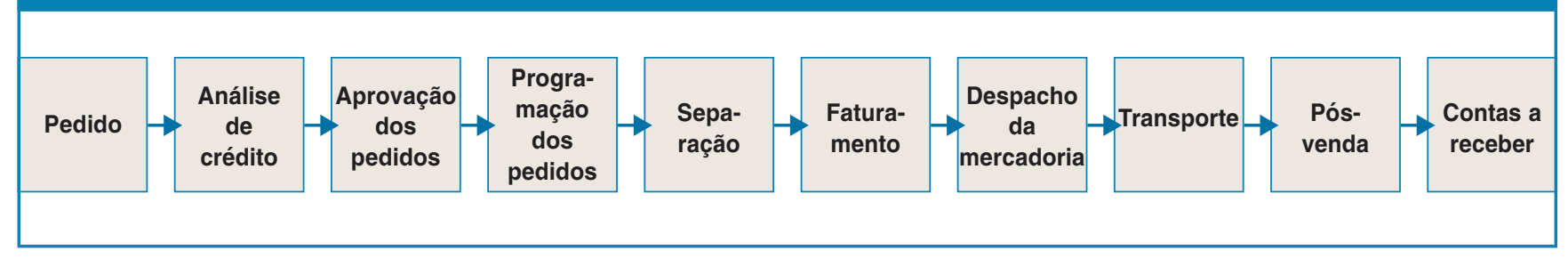


é identificado de maneira clara e indiscutível, e sua avaliação é difícil, já que existem componentes irracionais e emocionais.

De uma maneira simplificada, podemos dizer que o comportamento do cliente e suas expectativas se baseiam em algumas idéias simples. O cliente avalia cuidadosamente o que ele recebe em função do que paga e não enxerga aspectos internos da organização, por mais maravilhosos que eles possam parecer para o pessoal interno. Com raras exceções, o cliente não se interessa por detalhes de como a empresa produz o que oferece e, certamente, não compra para melhorar o resultado da empresa fornecedora.

\section{ORGANOGRAMAS E PROCESSOS}

Os organogramas não se prestam para a análise dos processos de negócio, pois não mostram como eles funcionam na prática nem como ocorrem na empresa. Os processos de negócio estão relacionados com o funcionamento da organização e geralmente não respeitam os limites estabelecidos pelos organogramas.

A organização de uma empresa por processos pode ter a aparência de uma estrutura funcional, com áreas funcionais bem definidas, mas com processos operando efetivamente de forma ortogonal ("na horizontal"). Não se trata de uma estrutura matricial, embora existam relações de dupla subordinação nas organizações por processos. Muitas vezes, as mesmas pessoas participam de vários processos simultaneamente.

$\mathrm{Na}$ prática, as áreas funcionais e suas chefias não desaparecem quando a organização se estrutura por processos. À medida que os process owners ("donos do processo") vão assumindo responsabilidade cada vez maior pelo projeto, pela estruturação e pelo funcionamento dos processos essenciais das empresas, os chefes das áreas funcionais se focam cada vez mais no treinamento e na capacitação do seu pessoal.

\section{ORGANIZAR POR PROCESSOS}

As estruturas organizacionais convencionais apresentam algumas características indesejáveis que comprometem o desempenho das empresas: elas priorizam as funções (áreas "verticais") em detrimento dos processos essenciais e exageram na divisão de tarefas, pois adotam o critério da otimização do funcionamento das áreas funcionais, o que leva à hiperespecialização. Nessa situação, as empresas têm estruturas hierárquicas rígidas e pesadas, repletas de "caixinhas" que executam pedaços fragmentados de processos de trabalho. Em cada "caixinha", predominam atividades padronizadas, controladas por vários níveis de chefia, cuja função principal é garantir o cumprimento das normas (Gonçalves e Dreyfuss, 1995). Além disso, essas empresas têm muitos níveis hierárquicos, o que introduz impedâncias e perdas de carga e usam mais recursos que o indispensável.

\section{As estruturas organizacionais convencionais têm terísticas operacionais indesejáveis.}


internos, resultando no produto ou serviço que é recebido por um cliente externo (Gonçalves, 2000).

Os processos de negócio são ligados à essência do funcionamento da organização (Dreyfuss, 1996). Eles são típicos da empresa em que operam e são muito diferentes de uma organização para outra. Eles têm o suporte dos sistemas informatizados que têm
(Gonçalves, 2000). Tentar enxergar o funcionamento das empresas do ponto de vista dos processos é a mais eficaz maneira de escapar da "abordagem das chaminés". ${ }^{3}$ De acordo com essa idéia, as empresas organizam-se geralmente como conjuntos de unidades funcionais verticais isoladas umas das outras, operando em paralelo, sem muita interligação. Nesse modelo, os processos precisam atravessar as fronteiras entre as "chaminés" funcionais, com sensível perda de tempo, qualidade e capacidade de atendimento.

A centralização das empresas nos seus processos levará a dese-

sido desenvolvidos ao longo de muitos anos de desafios e aperfeiçoamento. São os três ou quatro processos essenciais para a obtenção dos produtos ou serviços que são oferecidos aos clientes da empresa. São tipicamente processos de agregação de valor, e seu bom desempenho é crítico para o resultado da empresa.

Por outro lado, as atividades essenciais (aquelas atividades que são críticas para que sejam atingidos os objetivos da empresa) também podem, algumas vezes, ser chamadas de processos. Elas envolvem um conjunto de atividades operacionais, diversos níveis organizacionais e práticas gerenciais. Assim, elas são os processos que precisam ser executados para que a empresa exista (Bennis e Mische, 1995).

A importância dos processos essenciais na gestão das empresas vai da identificação e definição desses processos, passa pelo aperfeiçoamento de tais processos, pela priorização deles na gestão da empresa como um todo e chega até a redefinição da estrutura organizacional e do funcionamento da empresa em função dos seus processos básicos.

\section{ESTRUTURA ORGANIZACIONAL FUNCIONAL VERSUS ESTRUTURA ORGANIZACIONAL POR PROCESSOS}

A organização orientada por processos está surgindo como a forma organizacional dominante para o século XXI (Hammer, 1996). Abandonando a estrutura por funções, que foi a forma organizacional predominante nas empresas do século XX, as empresas estão organizando seus recursos e fluxos ao longo de seus processos básicos de operação. Sua própria lógica de funcionamento está passando a acompanhar a lógica desses processos, e não mais o raciocínio compartimentado da abordagem funcional.

Faz sentido definir uma estrutura organizacional em torno de um processo como fluxo de trabalho nhos organizacionais muito diferentes dos que conhecemos atualmente. O primeiro estágio, não apenas previsível mas que já está sendo adotado em muitas empresas, é o de redistribuir os recursos humanos e técnicos das empresas ao longo dos processos de negócio (Gonçalves, 1997b).

\section{GESTÃO POR PROCESSOS VERSUS ESTRUTURAÇÃO POR PROCESSOS}

Uma vez que as pessoas passam a trabalhar no processo, e não mais nas áreas da empresa que deixam de existir ou perdem muito de sua importância, a gestão dessas pessoas deve seguir modelos muito diferentes dos tradicionais. Num quadro de grande importância das pessoas na implementação de estruturas por processos e na gestão de organizações estruturadas de acordo com esse modelo, surgem perguntas inquietantes para as quais não temos, ainda, as melhores respostas. Como trabalham as pessoas num processo? A quem respondem? Como se coordena o trabalho realizado no processo? Como avaliar a adequação e o desempenho das pessoas na organização por processos? Como estruturar a carreira e o desenvolvimento dessas pessoas?

O funcionamento das empresas de acordo com a lógica dos processos implica a adoção de novas maneiras de trabalhar e de gerenciar o trabalho (Gonçalves, 1997b). A gestão por processos organizacionais difere da gestão por funções tradicional por pelo menos três motivos: ela emprega objetivos externos, os empregados e recursos são agrupados para produzir um trabalho completo e a informação segue diretamente para onde é necessária, sem o filtro da hierarquia (Stewart, 1992). O sucesso da gestão por processos está ligado ao esforço de minimizar a subdivisão dos processos empresariais.

O raciocínio baseado em processos é essencial para o "tombamento" ${ }^{4}$ das organizações: os membros da 
equipe dão início ao trabalho e asseguram-se de que o seu trabalho seja realmente realizado; estabelecem padrões para a avaliação da performance da equipe e de seus membros e dão apoio, encorajam e reconhecem as contribuições dos colegas de equipe. Essa forma de raciocínio dá maior ênfase ao processo que ao seu conteúdo.

Como os process owners não são chefes dos empregados que atuam nos seus processos, eles não podem mandar: têm que negociar e exercer influência. O modelo de gestão não pode se basear em comando e controle: precisa de negociação e colaboração (Hammer e Stanton, 1999). As pessoas precisam aprender a trabalhar em ambientes de colaboração.

A gestão por processos apóia-se no emprego de um sistema de medidas baseado em processos (processcentered measurement system).

Esses sistemas dão ênfase às variáveis e medidas referentes aos processos, e não às unidades verticais. ${ }^{5}$ As metas adotadas pela empresa, por exemplo, são as dos processos, e não aquelas adotadas tradicionalmente pelas áreas funcionais.

Modernas ferramentas de gestão empresarial, como os sistemas informatizados integrados do tipo ERP (Enterprise Resource Planning), como, por exemplo, o SAP, pressupõem que a gestão da empresa se dê por processos - e, portanto, só têm máximo resultado quando a empresa que os utiliza já está estruturada por processo - e que ela já seja administrada por eles.

Afinal, a empresa estruturada por processos não é necessariamente gerida por processos e vice-versa. Muitas vezes, a gestão das empresas ocorre de acordo com as idéias e os procedimentos antigos, típicos das organizações funcionais, mesmo quando elas estão querendo se organizar por processos. Outras vezes, as pessoas tentam administrar suas empresas por processos (inclusive com o emprego de sistemas informatizados especificamente projetados para isso) sem, no entanto, estruturá-las da maneira adequada. Os resultados, em ambos os casos, não são os melhores que se poderia pretender obter por causa da incompatibilidade entre modelo de gestão e modelo organizacional.

A essência da gestão por processo é a coordenação das atividades realizadas na empresa (Gonçalves, 1997a), em particular aquelas executadas por diversas equipes de diversas áreas. $\mathrm{O}$ funcionamento adequado da empresa e dos processos depende exatamente da competência com que essa coordenação é executada.

\section{ONDE ESTAMOS COM RELAÇÃO À ORGANIZAÇÃO POR PROCESSOS?}

Existem vários estágios na evolução de uma empresa em direção à organização por processos. Cada empresa atualmente se encontra em algum desses estágios e pode decidir passar para outro estágio que seja mais adequado às suas operações e perspectivas. Algumas empresas realmente evoluem de um estágio para outro ao longo de um trajeto. Outras passam diretamente de uma posição pouco evoluída para outra bem mais avançada. Nessa óptica, é importante que se tenha um quadro de referência que auxilie na avaliação do estágio de evolução da empresa em direção à organização por processos.

\section{A essência da gestão por processo é a coordenação das atividades realizadas na empresa, em particular aquelas executadas por diversas equipes de diversas áreas.}

Em princípio, podemos identificar pelo menos cinco estágios num espectro que vai de um modelo puramente funcional até o modelo essencialmente baseado em processos. As posições intermediárias correspondem a situações em que as empresas apresentam níveis variados de características típicas de organizações por processos.

O Quadro 1 descreve as várias etapas em que as empresas podem se encontrar em relação à organização por processos e apresenta algumas das características básicas dessas etapas tanto do ponto de vista do funcionamento das empresas como dos limites que é possível atingir em cada uma delas em termos de negócios.

As empresas que se encontram na Etapa A são aquelas que ainda não deram passos decididos em direção à estruturação por processos. Algumas se questionam sobre a validade de adotar uma estrutura por processos, outras só conseguem perceber os seus processos de manufatura, mas existem também aquelas empresas que, por diversos motivos, não chegaram a considerar seriamente a idéia de se reestruturar.

Nas organizações tradicionais, os processos são ignorados. Elas baseiam-se no fato de que os funcionários têm foco restrito, e a visão mais geral do quadro cabe unicamente aos gerentes. Os funcionários realizam uma tarefa comandados por seus chefes (Hammer, 1998). São empresas que ainda precisam passar por uma etapa de conscientização a respeito do assunto. Para essas empresas, as chances de uma mudança radical são muito limitadas. 
As empresas que se encontram na Etapa B já têm seus processos e subprocessos identificados, porém o foco do esforço ainda está centrado nas funções. Seus processos são enquadrados na estrutura funcional e geralmente empregam formas de trabalho antigas. As empresas dessa categoria limitam-se a aperfeiçoar os gargalos e obter mais eficiência operacional. Seu grande desafio é o mapeamento dos seus processos e a identificação dos processos essenciais em torno dos quais se organizar.

As empresas típicas da Etapa $\mathrm{C}$ são aquelas que, embora já tenham identificado seus processos e melhorado seus processos essenciais, ainda raciocinam por funções. Nessas empresas, o poder ainda se concentra nas unidades verticais, que resistem fortemente à idéia de "horizontalizar" a gestão. Geralmente, o máximo que podem tentar é aperfeiçoar seus processos essenciais, acrescentando-lhes tecnologia e cortando as ati- vidades e funções que não agregam valor para o cliente final. Em termos de passos adiante, podem adotar novos critérios para redistribuir seus recursos, de preferência, em função dos seus processos essenciais, e não das unidades verticais, e atribuir cada processo essencial a um process owner.

As empresas na Etapa D já tomaram todas as providências das etapas anteriores. Geralmente, distribuem seus recursos ao longo de seus processos essenciais e atribuem a responsabilidade da gestão de cada processo essencial a um process owner. No entanto, ainda trabalham com estruturas antiquadas e, apesar de estarem começando a obter resultados, a ênfase em processos provoca um alto desconforto na organização. Em termos de negócios, podem conseguir aperfeiçoar bastante o desempenho de processos isolados, integrando-os aos processos auxiliares. Sua grande tarefa, a partir desse ponto, é desenvolver um

Quadro 1 - Os estágios da evolução para a organização por processos

\begin{tabular}{|c|c|c|c|c|c|}
\hline & \multicolumn{5}{|c|}{ Etapas } \\
\hline & A & B & C & D & E \\
\hline $\begin{array}{l}\text { Onde } \\
\text { estamos }\end{array}$ & $\begin{array}{l}\text { Processos, que } \\
\text { processos? }\end{array}$ & $\begin{array}{l}\text { Identificamos } \\
\text { nossos processos, } \\
\text { subprocessos e } \\
\text { subsubprocessos }\end{array}$ & $\begin{array}{l}\text { Melhoramos os } \\
\text { processos } \\
\text { essenciais }\end{array}$ & $\begin{array}{l}\text { Redistribuímos } \\
\text { nossos recursos ao } \\
\text { longo de nossos } \\
\text { processos } \\
\text { essenciais e } \\
\text { atribuímos a } \\
\text { responsabilidade a } \\
\text { um process owner }\end{array}$ & $\begin{array}{l}\text { Nossa organização } \\
\text { foi desenhada pela } \\
\text { lógica dos nossos } \\
\text { processos } \\
\text { essenciais }\end{array}$ \\
\hline Comentários & $\begin{array}{l}\text { As empresas sequer } \\
\text { se deram conta } \\
\text { Em geral, as } \\
\text { empresas percebem } \\
\text { apenas os } \\
\text { processos de } \\
\text { manufatura, os } \\
\text { outros processos } \\
\text { são acessórios }\end{array}$ & $\begin{array}{l}\text { O foco do esforço } \\
\text { ainda está nas } \\
\text { funções } \\
\text { Os processos são } \\
\text { enquadrados na } \\
\text { estrutura funcional } \\
\text { A abordagem é } \\
\text { ampla demais } \\
\text { A forma de trabalho } \\
\text { é provavelmente } \\
\text { ainda antiga }\end{array}$ & $\begin{array}{l}\text { As empresas ainda } \\
\text { raciocinam por } \\
\text { funções, mesmo } \\
\text { que conheçam bem } \\
\text { seus processos } \\
\text { O uso de case } \\
\text { managers pode } \\
\text { melhorar o contato } \\
\text { com o cliente } \\
\text { O poder ainda } \\
\text { reside nas } \\
\text { unidades verticais }\end{array}$ & $\begin{array}{l}\text { Ainda é um } \\
\text { remendo, } \\
\text { construído sobre } \\
\text { uma estrutura } \\
\text { antiquada } \\
\text { As empresas } \\
\text { começam a obter } \\
\text { resultados da } \\
\text { ênfase em } \\
\text { processos, mas com } \\
\text { um alto desconforto } \\
\text { na organização } \\
\text { Implantação da } \\
\text { nova organização }\end{array}$ & $\begin{array}{l}\text { É a forma de } \\
\text { organização } \\
\text { indicada para a } \\
\text { gestão por processo } \\
\text { Áreas funcionais } \\
\text { praticamente não } \\
\text { existem } \\
\text { As metas e métricas } \\
\text { são definidas para } \\
\text { os processos }\end{array}$ \\
\hline $\begin{array}{l}\text { Até onde dá para } \\
\text { ir em termos de } \\
\text { negócio }\end{array}$ & $\begin{array}{l}\text { Enquanto o assunto } \\
\text { é pura manufatura, } \\
\text { as chances de } \\
\text { aperfeiçoamento } \\
\text { radical são } \\
\text { limitadas }\end{array}$ & $\begin{array}{l}\text { Aperfeiçoamento } \\
\text { de gargalos e } \\
\text { obtenção de } \\
\text { melhoras de } \\
\text { eficiência pontuais }\end{array}$ & $\begin{array}{l}\text { Aperfeiçoamento } \\
\text { dos processos } \\
\text { essenciais, cortando } \\
\text { as atividades e } \\
\text { funções que não } \\
\text { agregam valor }\end{array}$ & $\begin{array}{l}\text { Gestão de alguns } \\
\text { processos isolados } \\
\text { e integração com } \\
\text { processos auxiliares }\end{array}$ & $\begin{array}{l}\text { Gestão integrada } \\
\text { dos processos } \\
\text { essenciais }\end{array}$ \\
\hline
\end{tabular}


novo modelo estrutural, rompendo com as principais funções, reformulando os referenciais e os mecanismos de gestão e, finalmente, implantando a nova organização.

Finalmente, as empresas que se encontram na Etapa E são aquelas que já foram desenhadas pela lógica dos processos essenciais. Muitas vezes, são empresas novas, que não têm compromissos estruturais e organizacionais com o passado e que surgem já dentro de novos referenciais de organização e de negócio. São empresas capazes de realizar a gestão integrada de seus processos essenciais e de colher os resultados dessa integração. Sua grande tarefa é a monitoração permanente da definição do seu negócio e o ajuste dos processos adequados para seu negócio sempre que necessário, adequando a organização a cada momento, como um organismo vivo.

A principal utilidade desse modelo de classificação das empresas é a identificação do estágio em que se encontra a empresa de modo a ser possível avaliar como ela se situa com relação às demais e com respeito às expectativas dos seus dirigentes. Ele pode sugerir as providências necessárias para que a empresa mude de etapa e indicar o esforço necessário para essa transformação. É possível, também, utilizar esse modelo para avaliar o nível de preparo da alta gestão em função da etapa em que a empresa está e do desafio de mudar de etapa. Em determinadas situações, o modelo pode ajudar na identificação de indicadores de desempenho inadequados ou incongruentes.

\section{COMO MATERIALIZAR OS PRINCÍPIOS DE ORGANIZAÇÃO POR PROCESSOS}

Partimos da hipótese de que é possível para qualquer empresa mudar de etapa no espectro apresentado, caso isso seja considerado necessário e adequado. Nem sempre, no entanto, essa transição é suave, rápida e tranqüila. A Figura 2 mostra as ações básicas necessárias para buscar uma forma de organização baseada em processos a partir de cada uma das etapas do espectro. Evidentemente, o desafio é tanto maior quanto mais afastada da Etapa E a empresa se encontrar, e é possível que a avaliação do esforço necessário para mudar de etapa não recomende que a empresa tente chegar na Etapa E. É muito razoável para muitas empresas avançar uma ou duas etapas num primeiro passo e depois esperar para completar sua evolução quando for oportuno.

Geralmente, mudar a estrutura organizacional da empresa de um modelo funcional para uma estrutura por processos implica (Gonçalves, 1997a):

- atribuir a responsabilidade pelo andamento de cada processo essencial a um process owner;

- minimizar os deslocamentos de pessoas e as transferências de material (para reduzir esperas, erros e cruzamento de fronteiras), organizando as atividades ao longo de processos, e não por funções;

- maximizar o agrupamento das atividades, empregando equipes multifuncionais e pessoal polivalente;

- diminuir o gasto de energia por meio de atividades como, por exemplo, reunir as partes da empresa em um menor número de locais ou empregar maciçamente os recursos de tecnologia de informação para reduzir o transporte, a armazenagem e o deslocamento dos recursos e materiais empregados nos processos essenciais.

\section{É possível para qualquer empresa mudar} sua estrutura para se aproximar de uma organização por processos. 
o process owner típico estabelece as metas de desempenho do processo, define o seu orçamento operacional e aloca os recursos para o funcionamento do processo sob sua responsabilidade. Ele claramente assume diversas atribuições que são dos gerentes das unidades verticais nas estruturas organizacionais tradicionais.

Os process owners desempenham uma função permanente, responsável pelo projeto do processo essencial e pela sua monitoração e adaptação em função das condições que se alteram constantemente. Sua presença é indispensável e, se o process owner não estiver presente, o modelo convencional antigo reassume.

Algumas empresas utilizam a idéia do case manager para tentar dar agilidade aos seus processos de contato com os clientes externos. Procuram, com isso, oferecer aos clientes um ponto de contato único (single point of contact) com o processo (Davenport e Nohria, 1994). No entanto, essa é uma solução provisória e paliativa, já que o case manager não tem autoridade para interferir no processo.

Exatamente pelo fato de as organizações por processos exigirem que as pessoas trabalhem de maneira tão diferente, é freqüente perceber que faltam as ferramentas e os modelos sociais, psicológicos e humanos para ajustar os grupos internos às novas condições.

As alterações nos pressupostos que deram base para a formação inicial da empresa, tais como o perfil da concorrência, o mercado, a demanda dos clientes e a conjuntura do país, levam a empresa a procurar outra configuração que seja adequada à nova situação.

Entretanto, antes de repensar a organização em termos de sua estrutura, devemos preocupar-nos em analisar o negócio da empresa, descobrir se a defi-

Figura 2 - $\mathrm{O}$ que falta fazer para atingir uma organização por processos

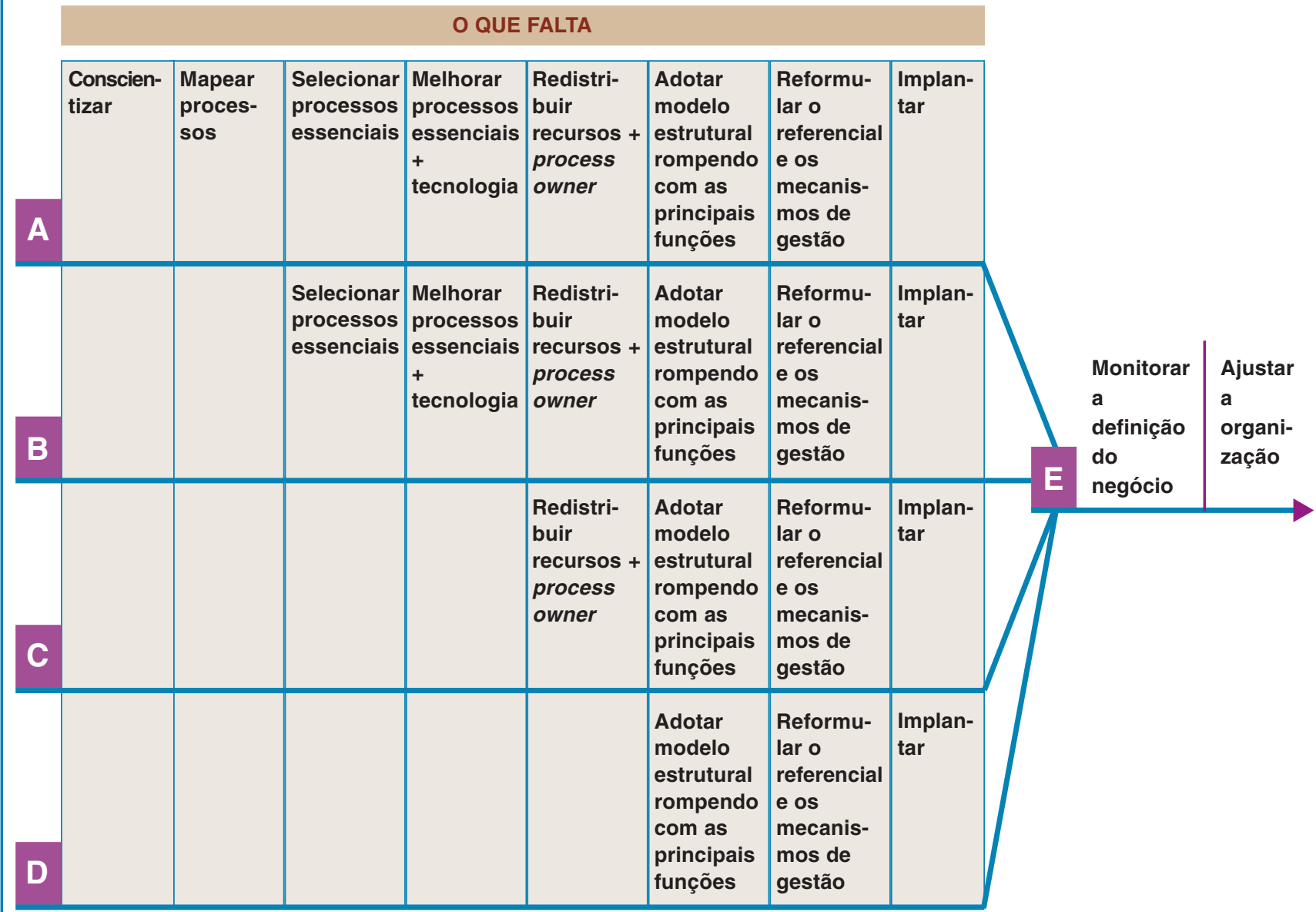


nição do negócio existente é adequada e se é o que a empresa quer. Assim, podemos definir o que a empresa quer ser e aonde quer chegar. Quando se sabe aonde se quer chegar, pode-se, então, questionar se os processos que a empresa tem são bons para o negócio escolhido e como melhorá-los em todas as dimensões. Não faz sentido investir esforço intelectual, físico e financeiro em operações que já não interessam à empresa (Gonçalves e Dreyfuss, 1995).

\section{COMO FAZER AS EMPRESAS PENSAREM EM TERMOS DE PROCESSOS?}

Muitas empresas não estão se preparando para se estruturarem por processos, embora pudessem conseguir bons resultados, porque nunca pensaram seriamente no assunto. Talvez elas pudessem ser levadas a pensar nessa alternativa se percebessem que parte de suas dificuldades ou de seu insucesso se deve à forma como são organizadas. Atrelar o sucesso de outras empresas à forma como elas são organizadas - por processos - poderia sugerir que a forma de as empresas se organizarem tem forte impacto nos resultados.

Parte do sucesso que as empresas japonesas tiveram com relação às suas concorrentes americanas nas décadas de 80 e 90 decorreu do fato de terem as empresas japonesas descoberto (ou pelo menos implementado) o gerenciamento de processos muito antes de as empresas ocidentais entenderem a que o assunto se referia (Davenport, 1994). O papel de destaque dado ao gerenciamento de processos na cultura corporativa japonesa garantiu que, em diversas ocasiões, muitas empresas daquele país tenham desenvolvido processos rápidos e eficientes em áreas-chave como desenvolvimento de produtos, logística, vendas e comercialização.

Os processos são a fonte das competências "específicas da empresa" que fazem a diferença em termos de concorrência, além da influência que podem ter a estratégia, os produtos, a estrutura e a indústria (Keen, 1997). Os processos não criam apenas as eficiências de hoje mas também garantem o futuro por meio de habilidades que se aplicam aos novos produtos. A rápida inovação dos processos pode resultar em capacitações organizacionais (Kanter, 1997) melhoradas que permitem, por exemplo, que os novos produtos sejam desenvolvidos mais rapidamente. É conhecido o caso das empresas industriais japonesas, que investiram $70 \%$ dos seus fundos de P\&D em inovação de processos, ao contrário das americanas, que investiram essa mesma proporção, mas no desenvolvimento de produtos. Os resultados muito superiores da indústria japonesa durante o período considerado provavelmente refletem as conseqüências dessa decisão.

\section{DECIDINDO-SE POR PROCESSOS}

Ainda é muito importante pensar em revisão de processos nas empresas. Depois da febre de reengenharia que assolou o mundo empresarial entre 1994 e 1997, muita gente pensou que o assunto estava terminado. Outros acharam que esse modelo logo seria substituído por outra idéia da moda. No entanto, todos os dias, percebemos que muitas empresas ainda 
já que vai sempre representar não apenas um grande esforço da parte de todos mas também uma razoável dose de risco para a empresa.

O Quadro 2 mostra uma abordagem simplificada da avaliação dos dez fatores mais importantes na decisão de adotar uma organização por processos. Com base nesses dez fatores, desenvolvemos o "Índice de Processibilidade", uma avaliação empírica da conveniência e mesmo da necessidade de estruturar a empresa por processos.

De acordo com o modelo, quanto maior o "Índi- ce de Processibilidade", mais para o extremo direito da escala e, portanto, mais intensa a recomendação por uma estrutura organizacional por processos. O índice é meramente indicativo, sem base científica que permita sua avaliação quantitativa.

$\mathrm{Na}$ aplicação desse modelo simplificado, devemos lembrar que cada negócio tem características muito particulares; o que é adequado em termos de agilidade, por exemplo, para uma empresa que produz por encomendas pode não ser adequado para uma que produz para estoque.

\section{Quadro 2 - Como calcular o Índice de Processibilidade}

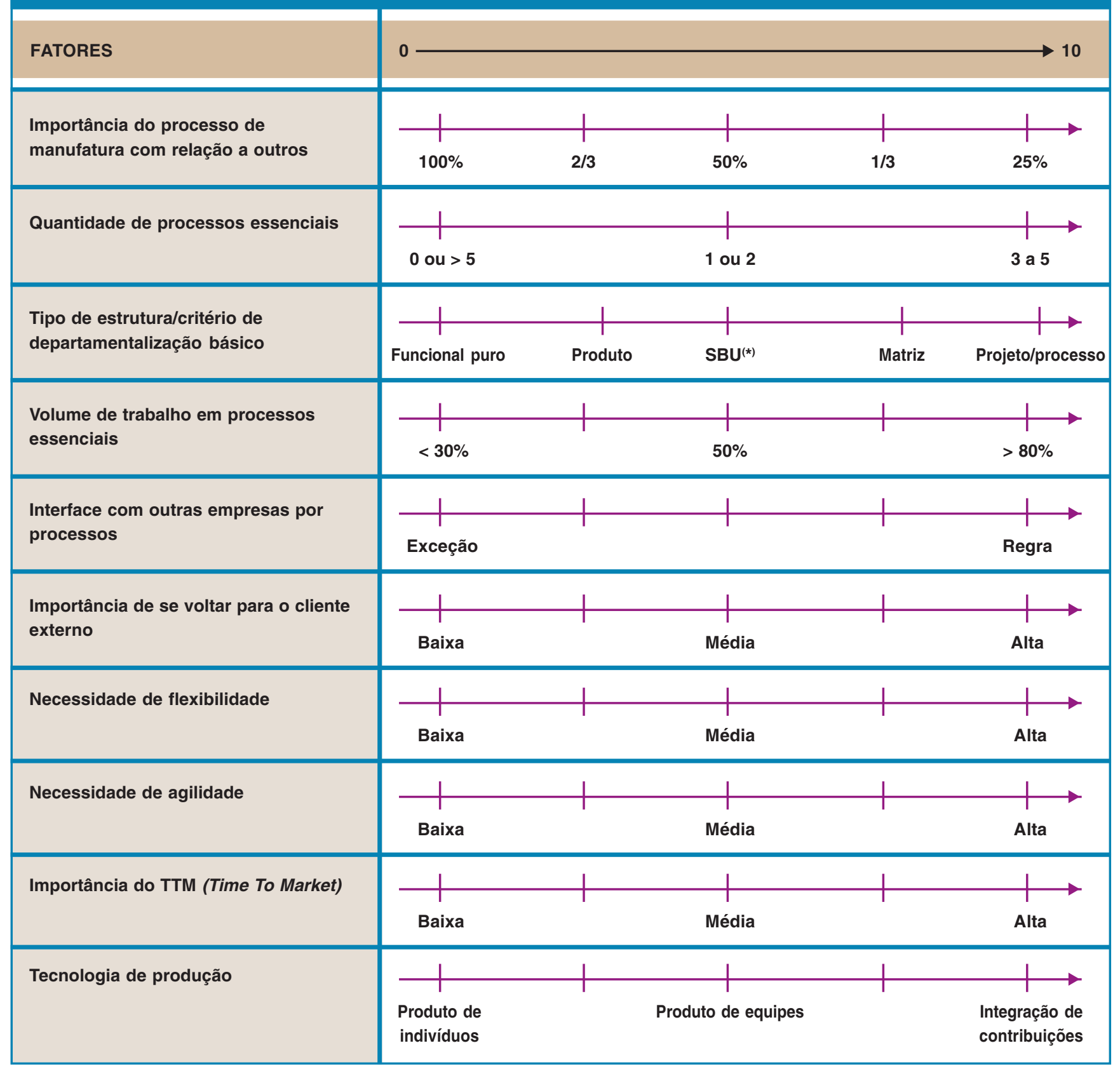

(*) Strategic Business Unit. 
O tempo necessário para conseguir mudar a organização de acordo com a necessidade identificada sugere que a análise desses pontos seja feita com referência a cinco ou dez anos no futuro.

\section{CONCLUSÕES}

Ao analisarmos a situação de uma empresa no que se refere ao seu funcionamento e à sua relação com os processos essenciais da sua indústria, vamos notar que a ênfase em processo não é sempre a única nem a melhor solução para qualquer situação. Na verdade, a opção pela organização por processos deve sempre ser feita depois de cuidadosa análise das condições e circunstâncias da empresa naquela situação.

Da mesma maneira, nem sempre é o caso de ir até o final da evolução para uma organização por processos, passando por todos os estágios do espectro de modelos organizacionais que discutimos aqui. Muitas vezes, a empresa vai considerar mais razoável para a sua situação particular evoluir apenas até um certo ponto do espectro e permanecer por lá durante algum tempo.

De modo geral, o futuro vai pertencer às empresas que consigam explorar o potencial da centralização das prioridades, das ações e dos recursos nos seus processos essenciais. As empresas do futuro deixarão de enxergar processos apenas na área industrial, serão organizadas em torno de seus processos não fabris essenciais e centrarão seus esforços em seus clientes (Gonçalves, 1997b). Para isso, deverão decidir por um modelo de organização por processos e tomar as providências para passar da sua estrutura atual para aquela que dará melhores resultados para a sua operação.

REFERÊNCIAS BIBLIOGRÁFICAS

BENNIS, Warren, MISCHE, Michael. The $21^{\text {st }}$ century organization. s.l. : Pfeifer, 1995.

DAVENPORT, Thomas. Reengenharia de processos. Rio de Janeiro : Campus, 1994.

DAVENPORT, Thomas, NOHRIA, Nitin. Case management and the integration of labour. SMR, v. 35, n. 2, p. 11-23, Winter 1994.

DREYFUSS, Cassio. As redes e a gestão das organizações. Rio de Janeiro : Guide, 1996.

GONCALVES, José Ernesto Lima. Organizando as empresas por processos. EAESP/FGV, 1997a. Notas de aula.

GONÇALVES, José Ernesto Lima. Os novos desafios da empresa do futuro. RAE - Revista de Administração de Empresas, v. 37, n. 3, p. 10-19, jul./set. 1997b.

GONÇALVES, José Ernesto Lima. A necessidade de reinventar as empresas. RAE - Revista de Administração de Empresas, v. 38, n. 2, p. 6-17, abr./jun. 1998.

NOTAS

1. Na concepção mais freqüente, processo é qualquer atividade ou conjunto de atividades que toma um input, adiciona valor a ele e fornece 0 output a um cliente específico. Mais formalmente, um processo é um grupo de atividades realizadas numa seqüência lógica com o objetivo de produzir um bem ou serviço que tem valor para um grupo específico de clientes. Os inputs podem ser materiais, equipamentos e outros bens tangíveis, mas também podem ser informações e conhecimento.
GONÇALVES, José Ernesto Lima. As empresas são grandes coleções de processo. RAE - Revista de Administração de Empresas, v. 40, n. 1, p. 6-19, jan./mar. 2000.

GONCALVES, José Ernesto Lima, DREYFUSS, Cassio. Reengenharia das empresas: passando a limpo. São Paulo : Atlas, 1995

HAMMER, M. Towards the twenty-first century enterprise. Boston : Hammer \& Co., 1996. Folheto.

HAMMER, M. A empresa voltada para processos. HSM Management, n. 9, ano 2, jul./ago. 1998.

HAMMER, M., STANTON, S. How process enterprises really work. Harvard Business Review, v. 77, n. 6, p. 108-118, Nov./Dec. 1999.

KANTER, Rosebeth Moss. Frontiers of management. Cambridge : Harvard Business School Press, 1997.
KEEN, Peter G. The process edge: creating value where it counts. Boston : Harvard Business School Press, 1997.

QUINN, James Brian. Intelligent enterprises. New York Free Press, 1992

RAMASWAMY, Rohit. Design and management of service processes. Reading : Addison Wesley, 1996.

RUMMLER, Geary, BRACHE, Alan. Improving performance. San Francisco : Jossey-Bass, 1990.

STEWART, Thomas. The search for the organization of tomorrow. Fortune, v. 125, n. 10, p. 92-98. May 18, 1992.

TENDICK, Jeffrey. Managing change or leading change... which way are you going to go? [1999]. Disponivel na Internet: <www.mattlorenz.com>.
2. Tempo de processamento é o efetivamente gasto na produção do resultado esperado, e tempo de ciclo é a duração da espera pelo resultado.

3. Esse "stovepipe approach" é mencionado por inúmeros autores como uma das mais típicas características das estruturas organizacionais convencionais, e o nome fo adotado pela semelhança gráfica dos organogramas característicos desse tipo de empresas com as chaminés das fábricas.
4. "Tombamento" ou "tilting" da organização corresponde ao movimento figurado de "virar" o organograma da empresa, conforme proposto por Graham, Morris e Melvin LeBaron em The horizontal revolution, publicado pela Jossey-Bass em 1994.

5. Neste artigo, chamamos de "unidades verticais" aquelas características das estruturas tradicionais, em contraposição ao funcionamento típico dos processos organizacionais que transcorrem na horizontal, ortogonalmente às unidades verticais. 